\title{
RECOMBINANT HUMAN COMPLEMENT C5A RECEPTOR ANTAGONIST REDUCES INFARCT SIZE AFTER SURGICAL REVASCULARIZATION
}

Robert D. Riley, MD

Hiroki Sato, MD, PhD

Zhi-Qing Zhao, MD, PhD

Vinod H. Thourani, MD

James E. Jordan, BS

Adolfo X. Fernandez, BS

Xin-Liang Ma, MD, PhD

Duncan R. Hite, MD

Dean F. Rigel, $\mathrm{PhD}$

Theodore C. Pellas, VMD, PhD

Jane Peppard, PhD

Kurt A. Bill, PhD

Rodney W. Lappe, $\mathrm{PhD}$

Jakob Vinten-Johansen, PhD
Objectives: This study tested the hypothesis that a recombinant human C5a antagonist, CGS 32359, attenuates neutrophil activation and reduces infarct size in a porcine model of surgical revascularization.

Methods: CGS 32359 (0.16-16 $\mu \mathrm{mol} / \mathrm{L})$ dose-dependently inhibited superoxide production by human $\mathrm{C} 5 \mathrm{a}$-activated porcine neutrophils $(18 \pm 3.7$ vs $1.6 \pm 0.5 \mathrm{nmol} / 5 \mathrm{~min} / 5 \times 10^{6}$ neutrophils; $\left.P<.05\right)$ and reduced neutrophil adherence to coronary endothelium from $194 \pm 9$ to $43 \pm 6$ neutrophils $/ \mathrm{mm}^{2}$ $(P<.05)$. The left anterior descending coronary artery was occluded for 50 minutes, after which saline solution $(n=8)$, mannitol-buffer vehicle $(n=9$, $102 \mathrm{mg} / \mathrm{kg}$ bolus, $102 \mathrm{mg} \cdot \mathrm{kg}^{-1} \cdot \mathrm{h}^{-1}$ ), or CGS 32359 (CGS, $\mathrm{n}=7,60 \mathrm{mg} / \mathrm{kg}$ bolus, $60 \mathrm{mg} \cdot \mathrm{kg}^{-1} \cdot \mathrm{h}^{-1}$ ) was infused. After ischemia, 1-hour arrest was achieved by means of multidose hypothermic $\left(4^{\circ} \mathrm{C}\right)$ blood cardioplegia, followed by 2.5 hours of off-bypass reperfusion. The ligature on the left anterior descending artery was released before the second infusion of cardioplegic solution.

Results: Area at risk was similar in all groups (saline solution, $27 \% \pm 2 \%$; mannitol-buffer vehicle, $26 \% \pm 2 \%$; CGS, $26 \% \pm 2 \%$ left ventricular mass). Infarct size (area necrosis/area at risk) was significantly reduced by CGS $(18 \% \pm 6 \%, P<.05)$ versus saline solution $(52 \% \pm 3 \%)$ and mannitol-buffer vehicle $(60 \% \pm 4 \%)$. Postischemic systolic shortening (sonomicrometry) in the area at risk was significantly improved with CGS $(0.8 \% \pm 0.9 \%)$ compared with saline solution $(-3.7 \% \pm 1.1 \%)$ and mannitol-buffer vehicle $(-6.4 \% \pm 1.0 \%)$. Myeloperoxidase activity from accumulated neutrophils was less in the ischemic zone of CGS $(0.014 \pm 0.002 \mathrm{U} / 100 \mathrm{mg}$ tissue; $P<$ $.05)$ than mannitol-buffer vehicle $(0.133 \pm 0.012 \mathrm{U} / 100 \mathrm{mg}$ tissue $)$.

Conclusions: We conclude that the recombinant human $\mathrm{C} 5$ a receptor antagonist CGS 32359 inhibits surgical ischemia-reperfusion injury after coronary occlusion. (J Thorac Cardiovasc Surg 2000;120:350-8)
$\mathrm{M}_{\mathrm{s}}$ ocardial ischemia and reperfusion stimulate the generation of complement by the alternative $\mathrm{e}^{1,2}$ and the classical ${ }^{3}$ pathways. In addition, the complement cascade is further augmented during cardiopulmonary bypass by interaction with extracorporeal surfaces. ${ }^{4-7}$

From The Cardiothoracic Research Laboratory, Carlyle Fraser Heart Center of Emory University School of Medicine, Atlanta, Ga; affiliations: Emory University School of Medicine, Atlanta, Ga (Z.-Q.Z., V.H.T., J.E.J., J.V.-J.); Bowman Gray School of Medicine, Winston-Salem, NC (R.D.R; H.S., J.E.J., A.X.F., D.R.H; Jefferson Medical College, Philadelphia, Pa (X.-L.M.); Novartis Institute for Biomedical Research, Summit, NJ (D.F.R., T.C.P, J.P., K.A.B., R.W.L).

Supported by a grant from Novartis Pharmaceuticals.

Received for publication Sept 3, 1999; revisions requested Dec 1,
The interaction between blood and foreign surfaces of extracorporeal circuits initiates deposition of the complement component $\mathrm{C} 3 \mathrm{~b}$, which in turn amplifies the alternative complement pathway, resulting in the release of $\mathrm{C} 3 \mathrm{a}$ and $\mathrm{C} 5 \mathrm{a}$ and formation of the membrane

1999; revisions received March 15, 2000; accepted for publication March 16, 2000.

Address for reprints: Jakob Vinten-Johansen, PhD, Director, Cardiothoracic Research Laboratory, Carlyle Fraser Heart Center of Emory University School of Medicine, 550 Peachtree St, NE, Atlanta, GA 30365.

Copyright (C) 2000 by The American Association for Thoracic Surgery

0022-5223/2000\$12.00+ $0 \quad \mathbf{1 2 / \mathbf { 1 } / \mathbf { 1 0 7 2 8 1 }}$

doi: $10.1067 / \mathrm{mtc} .2000 .107281$ 
attack complex (C5b-9). ${ }^{7}$ Plasma levels of C3a and, to a lesser extent, $\mathrm{C} 5 \mathrm{a}$, the plasma accumulation of which is prevented by avid binding to receptors, have been shown to be increased in patients undergoing cardiopulmonary bypass. ${ }^{7,8}$

Complement plays an important role in initiating and amplifying neutrophil activation during cardiopulmonary bypass. ${ }^{9,10}$ The anaphylatoxin $\mathrm{C} 5 \mathrm{a}$ activates both neutrophils and endothelial cells. Damage to postischemic myocardium and other organs has been correlated with both the generation of complement and the related activation and accumulation of neutrophils. ${ }^{11-13}$ The combined stimuli of myocardial ischemia-reperfusion and cardiopulmonary bypass may therefore exacerbate postischemic inflammatory responses in patients undergoing cardiopulmonary bypass for the surgical treatment of ischemic heart disease. Targeting complement components, particularly C5a, has been associated with a reduction in neutrophil activation and accumulation and a concomitant reduction in postischemic myocardial injury. ${ }^{13-17}$ However, few experiments have targeted the C5a anaphylatoxin by intervening at its receptor directly.

The present study tested the hypothesis that C5a receptor blockade with CGS 32359, a pure antagonist, inhibits neutrophil function (superoxide generation and adherence to endothelium) and in vivo manifestations of postischemic injury (infarct size and regional contractile dysfunction) after simulated surgical revascularization of regionally ischemic myocardium. CGS 32359 is a recombinant derivative of the human C5a molecule that binds to, but does not activate, the C5a receptor, thereby acting as an effective antagonist. ${ }^{18}$

\section{Methods \\ In vitro studies}

Superoxide production by porcine polymorphonuclear cells. Neutrophils from Yucatan micropigs (Panepinto Associates, Masonville, Colo) were isolated from peripheral arterial blood by using the Ficoll-Pacque (Sigma Chemical, St Louis, Mo) technique, as described previously. ${ }^{19}$ Final suspensions contained greater than $95 \%$ neutrophils, and cell viability was greater than $99 \%$, as determined by trypan blue exclusion. Superoxide anion production by $5 \times 10^{6}$ cells $/ \mathrm{mL}$ was measured spectrophotometrically $\left(\mathrm{V}_{\max }\right.$ Kinetic Microliter Plate Reader; Molecular Devices, Palo Alto, Calif) by using the superoxide dismutase-inhibitive reduction of ferricytochrome $c$ to ferrocytochrome $c$, as described previously. ${ }^{19}$ Results are reported as nanomoles of superoxide dismutase-inhibitive superoxide anion production per $5 \times 10^{6}$ polymorphonuclear cells (PMNs) per 5 minutes of reaction time.

$P M N$ adherence assay. Porcine PMNs $\left(4 \times 10^{5}\right.$ cells $\left./ \mathrm{mL}\right)$ labeled with Zynaxis PKH26 vital fluorescent dye (Zynaxis
Cell Science, Malvern, Pa) ${ }^{19}$ were incubated with coronary artery segments in culture dishes alone or in combination with different concentrations of CGS 32359. Recombinant human $\mathrm{C} 5 \mathrm{a}(\mathrm{rhC} 5 \mathrm{a} ; 100 \mathrm{nmol} / \mathrm{L}$ ) was used to activate the adhesion process. Adherence was determined by counting the number of PMNs adhering to the endothelial surface per square millimeter in 6 separate microscopic fields under epifluorescent microscopy (490-nm excitation, 504-nm emission), as described previously. ${ }^{19}$

\section{In vivo studies}

Surgical procedure. All animals received humane care in compliance with the "Guide for the Care and Use of Laboratory Animals" prepared by the Institute of Laboratory Animal Resources and published by the National Institutes of Health (National Institutes of Health publication No. 85-23, revised 1985). The protocol was approved by the Emory University Institutional Animal Care and Use Committee.

Micropigs weighing $10 \pm 3 \mathrm{~kg}$ were premedicated with intramuscular ketamine $(30 \mathrm{mg} / \mathrm{kg})$, xylazine $(20 \mathrm{mg} / \mathrm{kg})$, and diazepam $(0.2 \mathrm{mg} / \mathrm{kg})$. The left femoral artery and vein were catheterized for pressure monitoring and venous access for intravenous anesthesia (ketamine $8 \mathrm{mg} \cdot \mathrm{kg}^{-1} \cdot \mathrm{h}^{-1}$, xylazine 5 $\mathrm{mg} \cdot \mathrm{kg}^{-1} \cdot \mathrm{h}^{-1}$, and diazepam $0.2 \mathrm{mg} \cdot \mathrm{kg}^{-1} \cdot \mathrm{h}^{-1}$ supplemented with fentanyl citrate [2.0 $\mu \mathrm{g} / \mathrm{kg}$ every 30 minutes]) and fluid administration. The pig was intubated through a tracheotomy and the lungs were ventilated by a volume-cycled respirator with oxygen-enriched $(50 \%)$ room air. Ventilatory adjustments were made to maintain arterial $\mathrm{Po}_{2}$ greater than $100 \mathrm{~mm} \mathrm{Hg}$, $\mathrm{PCO}_{2}$ between 35 and $45 \mathrm{~mm} \mathrm{Hg}$, and $\mathrm{pH}$ between 7.35 and 7.45; acidemia was counteracted with sodium bicarbonate.

The chest was opened by means of a median sternotomy. Umbilical tape snares were placed loosely around the inferior and superior venae cavae, and the hemiazygous vein was ligated. The pericardium was opened and tented, and Millar MPC-500 temperature-compensating pressure transducers (Millar Instruments, Inc, Houston, Tex) were placed in the aorta through the right internal thoracic artery and in the left ventricle through an apical puncture. Pairs of sonomicrometer piezoelectric crystals were implanted in the subendocardium of the myocardium perfused by the distal left anterior descending (LAD) coronary artery (ischemia-reperfusion area) and within the distribution of the circumflex coronary artery (nonischemic area).

The animal was prepared for cardiopulmonary bypass before regional ischemia was imposed. An $8 \mathrm{~F}$ perfusion cannula was placed in the subclavian artery, and the right atrial appendage was cannulated with single-stage cannulas in the superior and inferior venae cavae. All cannulas were left in their most proximal position for later advancement to initiate cardiopulmonary bypass. A Sarns SMO/INF Infant Membrane Oxygenator (Sarns/3M, Ann Arbor, Mich) was primed with $300 \mathrm{~mL}$ of $6 \%$ Hetastarch (Abbott Laboratories, North Chicago, Ill) and 2 units of donor blood from littermate Panepinto Micropigs. A $12 \mathrm{~F}$ catheter was placed through the left ventricular (LV) apex to vent the left ventricle during cardiopulmonary bypass. 
Protocol. After baseline data were collected, the LAD was occluded for 50 minutes with the circulation intact (no cardiopulmonary bypass). The animal was randomized to 1 of 3 groups: saline control, mannitol-buffer vehicle, or CGS 32359. After 40 minutes of occlusion, either saline solution, mannitol-buffer vehicle, or CGS 32359 was administered as a bolus followed by continuous infusion; CGS 32359 was administered at a bolus dose of $60 \mathrm{mg} / \mathrm{kg}$ active compound and $60 \mathrm{mg} \cdot \mathrm{kg}^{-1} \cdot \mathrm{h}^{-1}$ continuous infusion. CGS 32359 was formulated in a mannitol-buffer lyophilizate containing $37 \%$ active compound by weight.

After 50 minutes of coronary occlusion, the caval cannulas were advanced, and cardiopulmonary bypass was initiated at a systemic pressure of $80 \mathrm{~mm} \mathrm{Hg}$. The aorta was crossclamped, and blood cardioplegic solution $\left(4^{\circ} \mathrm{C}, 10 \mathrm{mEq} / \mathrm{L}\right.$ $\mathrm{K}^{+}$) was delivered for 3 minutes at $50 \mathrm{~mm} \mathrm{Hg}$ through a catheter in the proximal aorta simultaneous with systemic cooling to $28^{\circ} \mathrm{C} \pm 1^{\circ} \mathrm{C}$. A low $\mathrm{K}^{+}(5 \mathrm{mEq} / \mathrm{L})$ blood cardioplegic solution was intermittently delivered at 20 and 40 minutes of arrest for 2 minutes each (total arrest time, 60 minutes). The LAD ligature was removed 5 minutes before the second delivery of cardioplegic solution to simulate revascularization of the target vessel. A final warm cardioplegic (10 $\mathrm{mEq} / \mathrm{L} \mathrm{K}^{+}$) formulation was delivered for 3 minutes, after which the crossclamp was immediately removed. After electromechanical reanimation was observed, systemic pressure was gradually increased from 50 to $80 \mathrm{~mm} \mathrm{Hg}$ over 5 minutes. The heart was reperfused for 30 minutes on bypass (designated as beating empty) and for 2 hours after discontinuation of bypass (designated as beating working).

Data collection. Hemodynamic data, including instantaneous LV pressure, arterial pressure, and ischemic zone and nonischemic zone regional wall motion (systolic shortening and diastolic characteristics), were collected at baseline, endischemia, and 30, 60, and 120 minutes after terminating cardiopulmonary bypass on an IBM-compatible computer by using analog-to-digital conversion (Data Translation DT2821) and SPECTRUM cardiodynamic data acquisition and analysis software (Wake Forest University, WinstonSalem, NC).

Area at risk and infarct size. At the end of each experiment, the LAD was religated, and $5 \mathrm{~mL}$ of Unisperse blue pigment (Ciba-Geigy, Newport, Del) was injected into the left atrium to demarcate the in vivo area at risk (AAR). The heart was arrested with intracardiac sodium pentobarbital, and the heart was excised. The unstained region of the myocardium (the AAR) was separated from the blue-stained nonischemic zone, and the AAR was incubated for 10 minutes in a $37^{\circ} \mathrm{C}$ $1 \%$ solution of buffered ( $\mathrm{pH} 7.4$ ) triphenyltetrazolium chloride. The area of necrosis relative to the AAR was determined gravimetrically, as previously described. ${ }^{20}$

Measurement of plasma CGS 32359. Concentrations of CGS 32359 in plasma were determined by an enzyme-linked immunosorbent assay with an antibody that reacted specifically with CGS 32359 but not with C5a. The working range of the assay was approximately 0.01 to $1 \mu \mathrm{g} / \mathrm{mL}$.
Cardiac myeloperoxidase activity. Tissue samples weighing approximately $0.4 \mathrm{~g}$ from the nonischemic zone and from the nonnecrotic and necrotic areas of the ischemic zone were analyzed spectrophotometrically for myeloperoxidase (MPO; in units per $100 \mathrm{mg}$ of tissue) activity as an assessment of neutrophil accumulation in the myocardium. ${ }^{21}$ One unit of MPO activity is defined as that enzyme activity degrading 1 mmol of $\mathrm{H}_{2} \mathrm{O}_{2}$ per minute at $25^{\circ} \mathrm{C}$.

Statistical analysis. All time-dependent variables were analyzed for time and group differences by 2-way analysis of variance for repeated measures (SigmaStat, SPSS Science, Chicago, Ill), followed by the Student-NewmanKeuls multiple range test. Single end-point variables (ie, AAR size and infarct size) were analyzed by 1-way analysis of variance followed by the Student-Newman-Keuls multiple range test. Exclusion criteria from further analysis included (1) failure to complete the protocol; (2) technical and surgical problems, which compromised the bypass or cardioplegia or led to failure to follow the protocol; (3) cardioversions greater than 4 during ischemia or reperfusion; or (4) failure to adequately demarcate the AAR with Unisperse Blue pigment. Means \pm SEMs are reported in the text and figures.

\section{Results}

In vitro studies. Superoxide radical generation in response to increasing concentrations of human C5a is shown in Fig 1, A. There was a concentration-dependent increase in superoxide radical generation, reaching a maximum at $1 \mu \mathrm{mol} / \mathrm{L}$ without further significant increase at $10 \mu \mathrm{mol} / \mathrm{L}$. A concentration of $100 \mathrm{nmol} / \mathrm{L}$ was selected for subsequent in vitro studies.

Fig $1, B$, shows the concentration-response curves for CGS 32359 on neutrophil superoxide radical generation stimulated by $100 \mathrm{nmol} / \mathrm{L}$ human C5a-stimulated neutrophils. Superoxide radical generation was inhibited to baseline (control) levels at a concentration of 8 $\mu \mathrm{mol} / \mathrm{L}$ CGS 32359, with no further inhibition with 16 $\mu \mathrm{mol} / \mathrm{L}$ concentration CGS 32359.

Fig 2, A, shows concentration-dependent stimulation of PMN adherence to porcine coronary artery endothelium by recombinant human C5a. Human C5a at $1 \mu \mathrm{mol} / \mathrm{L}$ gave maximal adherence, with no significant change at a higher concentration. Fig 2, $B$, shows inhibition of adherence of C5a-stimulated (100 $\mathrm{nmol} / \mathrm{L}$ ) neutrophils by increasing concentrations of CGS 32359. Adherence was decreased to unstimulated levels at a CGS 32359 concentration of $8 \mu \mathrm{mol} / \mathrm{L}$, with little further decrease at a concentration of 16 $\mu \mathrm{mol} / \mathrm{L}$.

In vivo studies. Eight experiments were included in the saline solution group, 9 in the mannitol-buffer vehicle group, and 7 in the CGS 32359 group. 
A

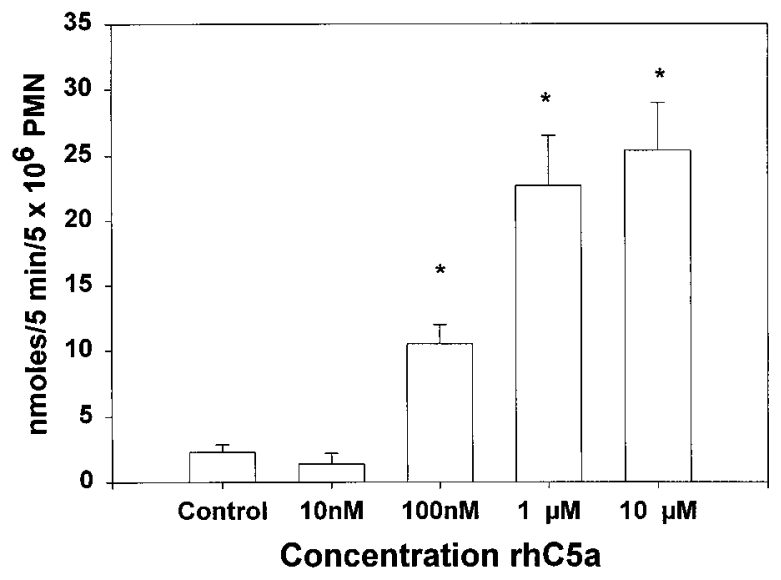

\section{B CGS 32359 on Superoxide Generation}

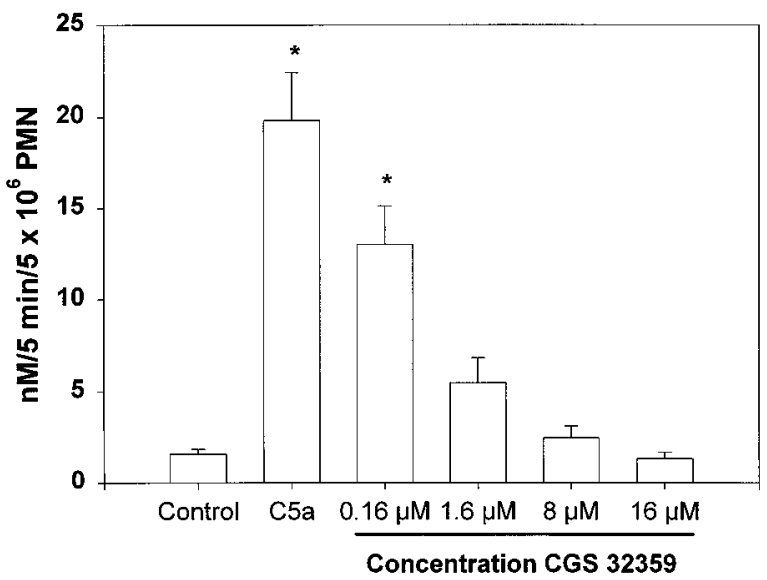

Fig 1. A, Superoxide radical generation by porcine PMNs stimulated by increasing concentrations of rhC5a. B, Concentration responses of C5a-stimulated superoxide radical generation by porcine PMNs and increasing concentrations of CGS 32359. $* P<.05$ versus control.

Plasma concentrations of CGS 32359. Systemic plasma concentrations of CGS 32359 generally increased during the experiment from the initial bolus $(22.0 \pm$ $12.7 \mu \mathrm{g} / \mathrm{mL})$ to the end of the experiment $(73.5 \pm 8.9$ $\mu \mathrm{g} / \mathrm{mL})$; the latter concentration represents approximately 4 to $4.5 \mu \mathrm{mol} / \mathrm{L}$. The average concentration of CGS 32359 in blood cardioplegic solution ranged between $71 \%$ and $82 \%$ of that in plasma at corresponding time points, consistent with the dilution associated with a 4:1 blood/crystalloid ratio.

Hemodynamics. Hemodynamic data are summarized in Table I. All 3 groups were comparable at baseline in heart rate; LV peak systolic pressure tended to be greater in the saline solution and mannitol-buffer vehicle groups than in the CGS 32359 group, but this was not significant $(P=.11)$. End-diastolic LV pressure was not significantly different among groups $(P=.74)$. Mean arterial pressure, however, was significantly greater in the saline solution group compared with the CGS group $(P=.04)$, as was positive and negative $\mathrm{dP} / \mathrm{dt}(P=.03$ each $)$.

During LAD occlusion, heart rate increased significantly in the mannitol-buffer vehicle group but showed no significant change in the saline solution or CGS groups. Heart rate was not statistically different among groups. LV end-diastolic pressure tended $(P=.11)$ to increase comparably from baseline values in all groups. Mean arterial pressure decreased significantly $(P=.04)$ in the saline solution group but not in the mannitolbuffer vehicle or CGS groups. However, there were no significant group differences at this time.
During 30 and 60 minutes of cardiopulmonary bypass, heart rate was significantly higher in the mannitol-buffer vehicle group compared with the saline solution group, but there were no group differences by 120 minutes of reperfusion. During all 3 time points of reperfusion, there were no group differences in LV enddiastolic pressure or mean arterial pressure.

Segmental function. At baseline, segment shortening in the ischemia-reperfusion zone was comparable among all 3 groups. During LAD occlusion, ischemic zone segment shortening decreased significantly $(P=$ .01 ) and to comparable values in all 3 groups (Fig 3, $A$ ). Segment shortening at all periods of reperfusion was significantly less than the respective baseline controls in all groups, suggesting contractile dysfunction across all groups. After the first 30 minutes of reperfusion off bypass, there was still systolic bulging evident in the saline solution and mannitol-buffer vehicle groups. In contrast, systolic shortening was positive and significantly greater $(P=.05)$ in the CGS 32359 group versus the mannitol-buffer vehicle group, which persisted for 120 minutes of reperfusion.

There were no group differences in systolic shortening at baseline. During coronary occlusion, there was no significant change in systolic shortening in the groups, although there was a tendency $(P=.09)$ for shortening to increase in the saline solution group. However, during 30 minutes of reperfusion off bypass, there was an increase in shortening in the CGS group, which was significantly greater $(P=.01)$ than that found in the saline solution and mannitol-buffer vehicle 
Table I. Hemodynamic variables during the course of the experiment

\begin{tabular}{clccc}
\hline \multicolumn{1}{c}{ Group } & Time & HR (beats/min $)$ & LVEDP $(\mathrm{mm} \mathrm{Hg})$ & MAP $(\mathrm{mm} \mathrm{Hg})$ \\
\hline Saline solution & Baseline & $92.9 \pm 8.0$ & $6.3 \pm 2.1$ & $114.6 \pm 5.0$ \\
& Ischemia & $86.6 \pm 4.2$ & $9.1 \pm 1.7$ & $80.6 \pm 8.0 \S$ \\
& BW30 & $97.9 \pm 5.8$ & $16.6 \pm 4.1$ & $81.1 \pm 5.5$ \\
& BW60 & $92.2 \pm 2.6$ & $16.2 \pm 2.9$ & $89.4 \pm 4.3$ \\
MW120 & $94.3 \pm 5.4$ & $14.7 \pm 2.9$ & $85.7 \pm 4.8$ \\
& Baseline & $76.5 \pm 7.9$ & $8.7 \pm 0.9$ & $103.6 \pm 5.1$ \\
& Ischemia & $103.2 \pm 8.6 \S$ & $11.3 \pm 1.8$ & $90.2 \pm 5.1$ \\
& BW30 & $118.9 \pm 6.5 \neq$ & $12.0 \pm 2.2$ & $86.9 \pm 5.4$ \\
CGS & BW60 & $110.9 \pm 4.8 \neq$ & $15.1 \pm 3.6$ & $88.6 \pm 5.4$ \\
& BW120 & $106.9 \pm 5.5$ & $8.3 \pm 1.4$ & $83.1 \pm 3.5$ \\
& Baseline & $83.6 \pm 5.0$ & $14.4 \pm 2.9$ & $93.8 \pm 5.2 *$ \\
& Ischemia & $96.6 \pm 7.3$ & $15.9 \pm 3.7$ & $78.1 \pm 9.4$ \\
& BW30 & $116.5 \pm 4.6 \dagger$ & $21.9 \pm 4.4$ & $78.9 \pm 4.2$ \\
& BW60 & $108.7 \pm 7.6$ & $14.9 \pm 2.3$ & $91.2 \pm 6.3$ \\
& BW120 & $105.9 \pm 4.6$ & $83.5 \pm 6.0$ \\
\hline
\end{tabular}

$H R$, heart rate; $L V E D P$, left ventricular end-diastolic pressure; $M A P$, mean arterial pressure; $B W$, Beating working off cardiopulmonary bypass (in minutes).

$* P<.05$ versus the saline solution group.

$\dagger P<.05$ versus the mannitol-buffer vehicle group.

$\ddagger P<.05$ versus the mannitol-buffer vehicle group versus the saline solution group.

$\S P<.05$ versus previous time for each group.

groups (Fig 3, B). Shortening in the saline solution group decreased by approximately $40 \%$, whereas shortening in the mannitol-buffer vehicle group remained comparable with that found during occlusion. However, any group differences disappeared at 60 and 120 minutes of reperfusion.

Infarct size. There were no statistically significant differences among groups in $\operatorname{LV}$ weight $(P=.06)$ and weight of the AAR (saline solution, $10.7 \pm 1.0 \mathrm{~g}$; mannitol-buffer vehicle, $7.5 \pm 0.9 \mathrm{~g}$; CGS $32359,8.3 \pm 1.0 \mathrm{~g}$; $P=.07)$. The AAR normalized for $\mathrm{LV}$ mass showed no differences among the 3 groups (Fig 4). The area of necrosis normalized either by the LV mass (Fig 4, middle panel) or the AAR (Fig 4, bottom panel) was not significantly different between the saline solution and mannitol-buffer vehicle groups. However, infarct size was significantly less in the CGS 32359-treated group ( $P=$ .03 ), whether expressed relative to LV mass or AAR.

MPO activity. Because of technical difficulties, the MPO values in the saline solution group are not reported. However, values for the mannitol-buffer vehicle group may serve as a control. As shown in Table II, there was no significant difference between groups in MPO activity in the nonischemic myocardium $(P=$ .99). In the mannitol-buffer vehicle group, MPO activity in the nonnecrotic and necrotic AARs were significantly greater than that in the nonischemic zone. MPO activity was significantly $(P=.01)$ less in the nonnecrotic and necrotic areas at risk of the CGS 32359 group compared with the same regions in the mannitolbuffer vehicle group.

\section{Discussion}

Complement is involved in the pathophysiology of myocardial postischemic injury, infarction, and multiple organ damage referred to as postperfusion syndrome..$^{22}$ On an organ level, complement products may be activated locally during myocardial ischemia ${ }^{1-3}$ but are further activated during reperfusion. ${ }^{23}$ Complement products, such as C3a and C5a, are also activated with exposure of blood to extracorporeal surfaces, notably oxygenators, during cardiopulmonary bypass. ${ }^{6,10}$ Complement C5a activates neutrophils, consistent with data shown in Figs 1 and 2 of the present study, and the activated neutrophils subsequently induce endothelial injury and damage to function and morphology of parenchymal tissue. Surgical revascularization of acute evolving infarction with cardiopulmonary bypass and cardioplegia techniques may therefore represent synergistic stimuli from the pathogenesis of infarction and responses to extracorporeal circulation for complement production and consequent complement-mediated injury (direct injury and neutrophil induced). ${ }^{6}$ This complement-mediated injury may aggravate ischemia-reperfusion injury in the surgical setting and hence may counteract some of the benefits of surgical revascularization. The present study has shown that the selective C5a receptor antagonist CGS 32359 attenuated neutrophil superoxide generation and adherence to coronary artery endothelium in vitro and improved regional postischemic functional recovery and decreased infarct size in the at-risk myocardium associated with an attenuation of neutrophil accumulation in an in vivo model of surgical revascularization. The 


\section{A C5a-stimulated PMN Adherence}

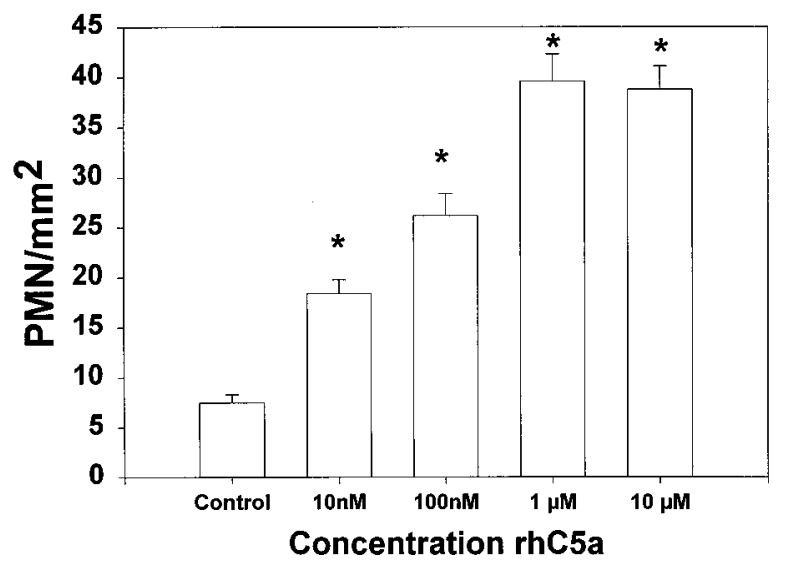

B CGS 32359 on C5a-Stimulated Neutrophil Adherence

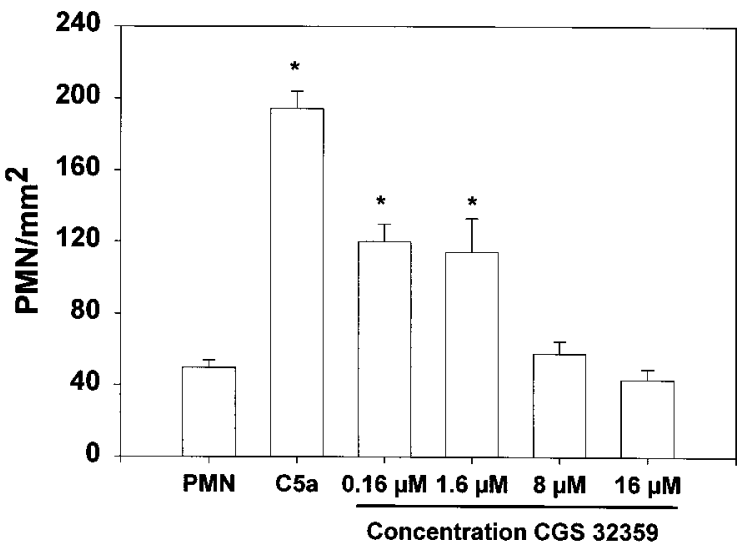

Fig 2. A, Stimulation of porcine PMN adherence to porcine coronary artery endothelium by increasing concentrations of rhC5a. B, Inhibition by CGS 32359 on adherence of C5a-stimulated porcine PMNs to unstimulated coronary artery endothelium. $C 5 a$, PMN stimulated with $100 \mathrm{nmol} / \mathrm{L}$ rhC5a, no treatment. $* P<.05$ versus control.

recovery of regional contractile function with CGS 32359 was modest, although statistically significant, and may be of little biologic significance or clinical significance to the generation of cardiac output. The functional recovery (systolic shortening) was independent of hemodynamic status.

CGS 32359 is a dimeric derivative of C5a with a truncated C-terminal end. It is a pure C5a receptor antagonist that binds avidly to human neutrophils and inhibits the binding of iodine 125-labeled rhC5a to human neutrophils with a $\mathrm{K}_{\mathrm{i}}$ of $2 \mathrm{pmol} / \mathrm{L} .{ }^{18}$ CGS 32359 inhibits C5a-stimulated intracellular calcium mobilization with an inhibitory constant $\left(\mathrm{K}_{\mathrm{i}}\right)$ of $13 \pm 4 \mathrm{nmol} / \mathrm{L}$ and attenuates CD11B integrin upregulation $\left(\mathrm{K}_{\mathrm{i}}=1 \pm\right.$ $0.2 \mathrm{nmol} / \mathrm{L})$, superoxide generation $\left(\mathrm{K}_{\mathrm{i}}=282 \mathrm{nmol} / \mathrm{L}\right)$, and chemotaxis $\left(\mathrm{K}_{\mathrm{i}}=7 \pm \mu \mathrm{mol} / \mathrm{L}\right)$ in human neutrophils. Although we used human recombinant C5a to activate porcine neutrophils in the present study, rather than using porcine $\mathrm{C} 5 \mathrm{a}$, it is expected that human $\mathrm{C} 5 \mathrm{a}$ has similar responses on porcine neutrophils because chemical structure and receptor homology are conserved between the two species. Accordingly, Pellas and colleagues ${ }^{18}$ attenuated neutropenia induced by recombinant human $\mathrm{C} 5 \mathrm{a}$ in a porcine (micropigs) model using CGS 32359, the same species used in the present study, at a dose of $5 \mathrm{mg} / \mathrm{kg}$. Recombinant human C5a $(5 \mathrm{ng} / \mathrm{kg})$ caused circulating neutrophil counts in anesthetized micropigs to decrease by $32 \pm$ $3 \%$, which was inhibited by CGS $32359 .{ }^{18}$ Consistent with homology between human and porcine receptor-mediated actions of $\mathrm{C} 5 \mathrm{a}$, the present study demon- strated that CGS 32359 inhibited in vitro rhC5a-stimulated porcine neutrophil superoxide radical production and adherence to porcine coronary artery endothelium in a concentration-dependent manner. However, we did not test CGS 32359 on porcine C5a in vitro in the present study.

In contrast to other studies in which complement therapy was initiated before ischemia (ie, pretreatment), ${ }^{17,24}$ the C5a antagonist CGS 32359 was effective at reducing infarct size when administered after coronary occlusion but before surgical reperfusion. The underlying mechanism may include a reduction in neutrophil-mediated injury and resultant reduction in infarction. This time window of drug administration is applicable to surgical revascularization procedures in which therapeutic agents can be administered before induction of cardiopulmonary bypass. This study provides strong evidence that $\mathrm{C} 5 \mathrm{a}$, through receptor-mediated actions, participates in surgically related postperfusion and ischemia-reperfusion injury and that $\mathrm{C} 5 \mathrm{a}$ receptor antagonism initiated before surgical reperfusion is an effective therapeutic approach.

Complement fractions act directly on both neutrophils and vascular endothelium to trigger neutrophil activation and adherence to endothelium. ${ }^{25,26} \mathrm{C} 5 \mathrm{a}$, unlike $\mathrm{C} 3 \mathrm{a}$, is a strong chemotactic factor ${ }^{16,18}$ and promotes adherence to the vascular endothelium. In addition, C5a stimulates the upregulation of the cell surface glycoprotein complexes $\mathrm{CD} 11 \mathrm{a} / \mathrm{CD} 18$ and $\mathrm{CD} 11 \mathrm{~b} / \mathrm{CD} 18$ on neutrophils. $^{27}$ This upregulation is a rapid response to $\mathrm{C} 5 \mathrm{a}$ involving translocation of preformed integrin complexes 


\section{A Ischemic Zone Systolic Shortening}

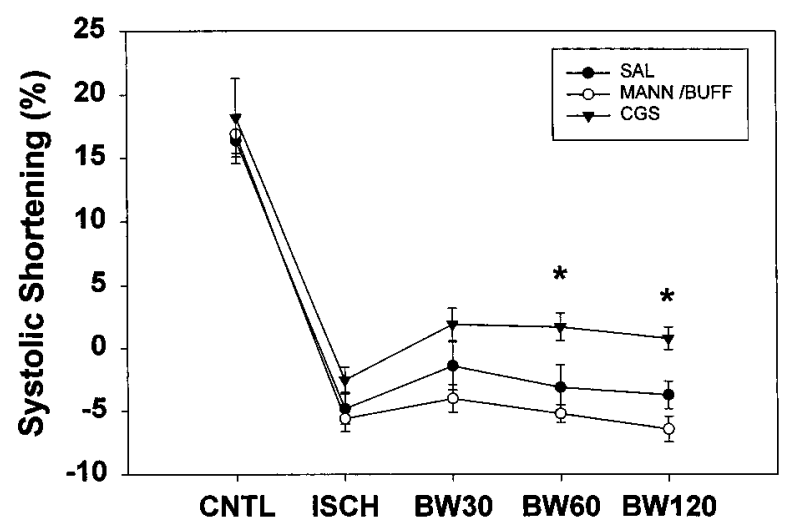

B Non-ischemic Zone Systolic Shortening

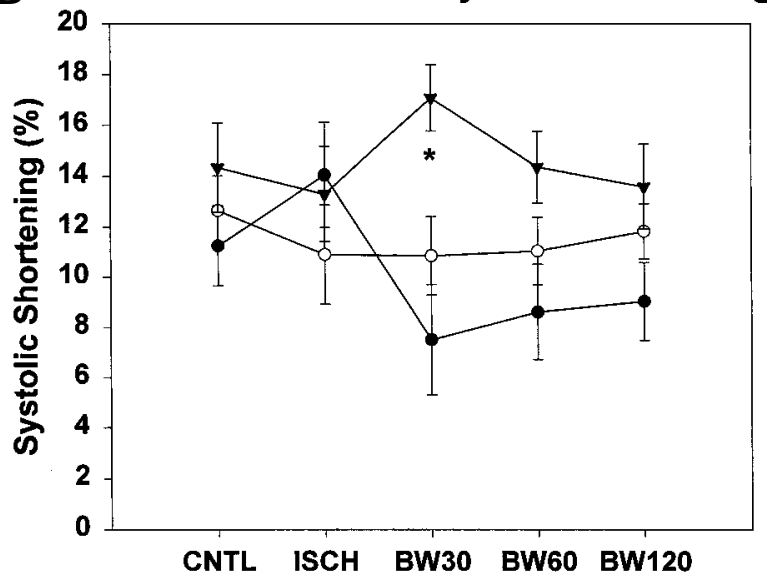

Fig 3. Segmental shortening in the ischemia-reperfusion AAR (A) and in the nonischemic zone (B) during the course of the experiment. $S A L$, Saline solution group; MANN/BUFF, mannitol-buffer vehicle group; $C G S$, CGS 32359 group; $C N T L$, control or baseline; $I S C H$, coronary occlusion; $B W 30, B W 60$, and $B W 120$, minutes after discontinuation of cardiopulmonary bypass. $* P<.05$ versus the saline solution and mannitol-buffer vehicle groups.

Table II. Myocardial MPO activity as an index of neutrophil accumulation within the nonischemic myocardium and the $A A R$

\begin{tabular}{|c|c|c|c|}
\hline Group & Nonischemic & Nonnecrotic AAR & Necrotic AAR \\
\hline Mannitol-buffer & $0.026 \pm 0.00865$ & $0.113 \pm 0.0773$ & $0.101 \pm 0.0227$ \\
\hline CGS 32359 & $0.026 \pm 0.00501$ & $0.014 \pm 0.0021^{*}$ & $0.0310 \pm 0.0119 *$ \\
\hline
\end{tabular}

All values are given as units per $100 \mathrm{mg}$ of tissue.

$* P<.05$ versus the mannitol-buffer vehicle group.

to the neutrophil plasma membrane. C5a is also a potent agonist of P-selectin surface expression on endothelial cells. Therefore, C5a promotes activation of both cell types involved in inflammatory-related neutrophilendothelial cell interactions. Our in vitro studies are consistent with this involvement of C5a by demonstrating that treatment of neutrophils with rhC5a increases superoxide radical generation (Fig 1, $A$ ) and adherence to coronary vascular endothelium (Fig $2, A$ ), which was inhibited by the highly selective $C 5$ a receptor antagonist CGS 32359 (Figs 1, $B$, and 2, B). The significant reduction in neutrophil accumulation observed in the in vivo AAR of the CGS 32359-treated group may have been the result of a direct inhibition of C5a-mediated neutrophil activation or attenuation of adherence to coronary artery and venous endothelium and subsequent accumulation in this area. Although studies have shown that both ischemia-reperfusion and cardiopulmonary bypass increase $\mathrm{C} 5 \mathrm{a}$ generation, we did not measure local or circulating C5a or C5a-desArg in the present experiment.
Inhibition of complement-mediated mechanisms have been shown to be beneficial in reducing infarct size and contractile dysfunction in a number of studies. ${ }^{23,26,28}$ Accordingly, inhibition of formation of complement components by complement receptor type $1^{15,29}$ or with glycosaminoglycans (heparin and sulfated derivatives $)^{30}$ or binding of complement components into nonactive complexes (complement-antibody complexes) ${ }^{17}$ have been therapeutically beneficial. Pretreatment with a recombinant human soluble complement receptor type $1^{29}$ reduced complement-activated neutrophil superoxide generation and postischemic contractile dysfunction. In a study by Amsterdam and colleagues,${ }^{17}$ pretreatment with a monoclonal antibody to C5a reduced infarct size by $38 \%$ but did not alter neutrophil accumulation in the AAR. However, the monoclonal antibody to C5a inhibited C5a-induced neutrophil aggregation, chemotaxis, and superoxide generation in vitro in agreement with our observations. In a porcine model of global ischemia and cardioplegia protection, Tofukuji and colleagues ${ }^{31}$ reported that a 
A

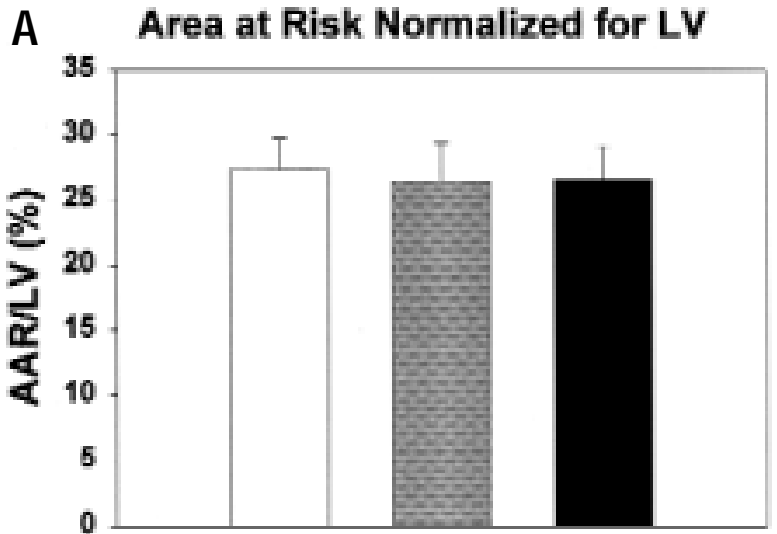

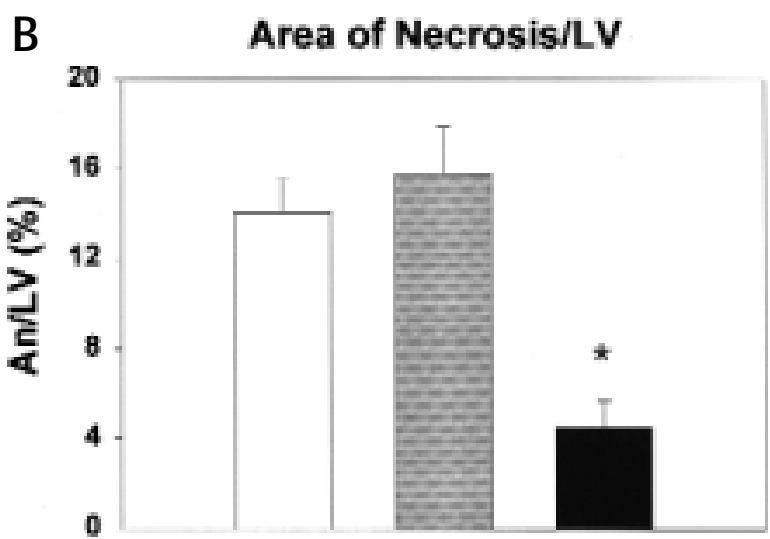

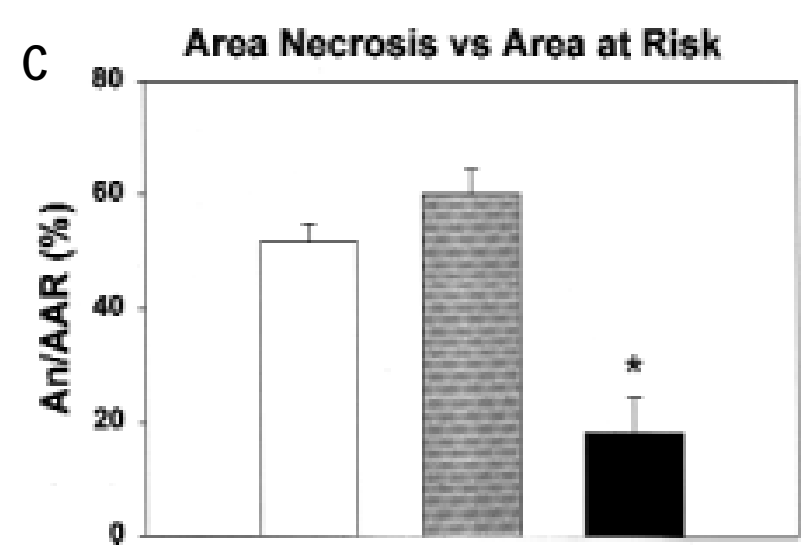

Fig 4. Infarct size data as a percentage of either LV mass (in grams) or AAR. A, AAR normalized for mass of the $\mathrm{LV} ; \mathbf{B}$, area of necrosis $(A n)$ normalized for LV mass; C, area of necrosis normalized for AAR. Open bar, Saline solution group; gray bar, mannitol-buffer group; black bar, CGS 32359 group. $* P<.05$ versus the saline solution and mannitol-buffer vehicle groups.

monoclonal antibody to C5a reduced neutrophil accumulation in myocardial tissue postischemically, which is consistent with observations in the present study using the receptor antagonist CGS 32359. In addition, Tofukuji and colleagues also showed that postischemic coronary arteriolar endothelial function was improved with a monoclonal antibody to C5a. In a clinical study, Fitch and colleagues ${ }^{14}$ demonstrated that a humanized antibody to C5a reduced leukocyte activation, sC5b-9 production and CK-MB release, and attenuated neurocognitive defect in patients undergoing cardiopulmonary bypass. Hence, these studies and the present study support the concept that attenuating C5 and C5a is an effective therapeutic approach to reducing postischemic injury in the surgical setting where cardiopulmonary bypass is used.

In summary, the human recombinant C5a antagonist CGS 32359 inhibited neutrophil superoxide radical production and adherence to coronary artery endothelium stimulated by $\mathrm{C} 5 \mathrm{a}$ in porcine in vitro assays. When given as an intravenous adjunct before surgical revasculariza- tion, CGS 32359 significantly reduced infarct size and modestly improved regional systolic functional recovery independent of hemodynamic changes. A reduction in MPO activity in the AAR in CGS 32359-treated hearts in conjunction with the in vitro data suggests a neutrophilmediated mechanism of cardioprotection. The present study strongly suggests that C5a receptor antagonists administered at a clinically relevant time (before surgical reperfusion and as an adjunct to cardioplegia) may be an important therapeutic strategy in reducing the cardiac consequences of postischemic injury in situations where direct and neutrophil-mediated effects of complement contribute to postischemic tissue damage.

We thank William Boyar for his contribution to the development of CGS 32359. We also thank Ms Gail Nechtman for assistance in manuscript preparation and Ms Sara Katzmark, Ms Jill Robinson, and Ms L. Susan Schmarkey for their technical and organizational assistance. Finally, we thank the Carlyle Fraser Heart Center for continued support of the research effort. 


\section{REFERENCES}

1. McManus LM, Kolb WP, Crawford MH, O'Rourke RA, Grover FL, Pinckard RN. Complement localization in ischemic baboon myocardium. Lab Invest 1983;48:436-47.

2. Crawford MH, Grover FL, Kolb WP, McMahan A, O'Rourke RA, McManus LM, et al. Complement and neutrophil activation in the pathogenesis of ischemic myocardial injury. Circulation 1988;78:1449-58.

3. Rossen RD, Swain JL, Michael LH, Weakley S, Giannini E, Entman ML. Selective accumulation of the first component of complement and leukocytes in ischemic canine heart muscle. Circ Res 1985;57:119-30.

4. Tennenberg SD, Clardy CW, Bailey WW, Solomkin JS. Complement activation and lung permeability during cardiopulmonary bypass. Ann Thorac Surg 1990;50:597-601.

5. Videm V, Fosse E, Mollnes TE, Garred P, Svennevig JL. Complement activation with bubble and membrane oxygenators in aortocoronary bypass grafting. Ann Thorac Surg 1990;50:387-91.

6. Kirklin JK, Westaby S, Blackstone EH, Kirklin JW, Chenoweth $\mathrm{DE}$, Pacifico AD. Complement and the damaging effects of cardiopulmonary bypass. J Thorac Cardiovasc Surg 1983;86:84557.

7. Steinberg JB, Kapelanski DP, Olson JD, Weiler JM. Cytokine and complement levels in patients undergoing cardiopulmonary bypass. J Thorac Cardiovasc Surg 1993;106:1008-16.

8. Ovrum E, Mollnes TE, Fosse E, Åm Holen E, Tangen G, Abdelnoor M, et al. Complement and granulocyte activation in two different types of heparinized extracorporeal circuits. J Thorac Cardiovasc Surg 1995;110:1623-32.

9. Gillinov AM, Redmond JM, Winkelstein JA, Zehr KJ, Herskowitz A, Baumgartner WA, et al. Complement and neutrophil activation during cardiopulmonary bypass: a study in the complement-deficient dog. Ann Thorac Surg 1994;57:345-52.

10. Chenoweth DE. Complement activation during cardiopulmonary bypass. In: Utley JR, Betleski R, editors. Pathophysiology and techniques of cardiopulmonary bypass. Baltimore: Williams \& Wilkins; 1983. p. 49-60.

11. Simpson PJ, Mickelson J, Fantone JC, Gallagher KP, Lucchesi BR. Iloprost inibits neutrophil function in vitro and in vivo and limits experimental infarct size in canine heart. Circ Res 1987;60:666-73.

12. Romson JL, Hook BG, Rigot VH, Schork MA, Swanson DP, Lucchesi BR. The effect of ibuprofen on accumulation of indium111-labeled platelets and leukocytes in experimental myocardial infarction. Circulation 1982;66:1002-11.

13. Cai Q, Takemura G, Ashraf M. Antioxidative properties of histidine and its effect on myocardial injury during ischemia/reperfusion in isolated rat heart. J Cardiovasc Pharmacol 1995;25:147-55.

14. Fitch JCK, Rollins S, Matis L, Alford B, Aranki S, Collard CD, et al. Pharmacology and biological efficacy of a recombinant, humanized, single-chain antibody C5 complement inhibitor in patients undergoing coronary artery bypass graft surgery with cardiopulmonary bypass. Circulation 1999;100:2499-506.

15. Smith EF 3rd, Griswold DE, Egan JW, Hillegass LM, Smith RA, Hibbs MJ, et al. Reduction of myocardial reperfusion injury with human soluble complement receptor type 1 (BRL 55730). Eur J Pharmacol 1993;236:477-81.

16. Vakeva AP, Agah A, Rollins SA, Matis LA, Li L, Stahl GL. Myocardial infarction and apoptosis after myocardial ischemia and reperfusion: role of the terminal complement components and inhibition by anti-C5 therapy. Circulation 1998;97:2259-67.

17. Amsterdam EA, Stahl GL, Pan HL, Rendig SV, Fletcher MP, Longhurst JC. Limitation of reperfusion injury by a monoclonal antibody to C5a during myocardial infarction in pigs. Am J Physiol 1995;268:H448-57.

18. Pellas TC, Boyar W, von Oostrum J, Wasvary J, Fryer LR, Pastor $\mathrm{G}$, et al. Novel C5a receptor antagonists regulate neutrophil functions in vitro and in vivo. J Immunol 1998;160:5616-21.

19. Zhao Z-Q, Sato H, Williams MW, Fernandez AZ, VintenJohansen J. Adenosine $\mathrm{A}_{2}$-receptor activation inhibits neutrophilmediated injury to coronary endothelium. Am J Physiol 1996;271:H1456-64

20. Jordan JE, Zhao Z-Q, Sato H, Taft S, Vinten-Johansen J. Adenosine $\mathrm{A}_{2}$ receptor activation attenuates reperfusion injury by inhibiting neutrophil accumulation, superoxide generation and coronary endothelial adherence. J Pharmacol Exp Ther 1997;280:301-9

21. Sato H, Zhao Z-Q, McGee DS, Williams MW, Hammon JW, Jr, Vinten-Johansen J. Supplemental l-arginine during cardioplegic arrest and reperfusion avoids regional postischemic injury. $\mathrm{J}$ Thorac Cardiovasc Surg 1995;110:302-14.

22. Miller BE, Levy JH, Martin S, Dehoux M, Chatel D, Brient N, et al. The inflammatory response to cardiopulmonary secretion during normothermic bypass. J Cardiothorac Vasc Anesth 1997;11: 355-66.

23. Kilgore KS, Friedrichs GS, Homeister JW, Lucchesi BR. The complement system in myocardial ischaemia/reperfusion injury. Cardiovasc Res 1994;28:437-44.

24. Gillinov AM, DeValeria PA, Winkelstein JA, Wilson I, Curtis WE, Shaw D, et al. Complement inhibition with soluble complement receptor Type 1 in cardiopulmonary bypass. Ann Thorac Surg 1993;55:619-24.

25. Boyle EM, Pohlman TH, Johnson MC, Verrier ED. Endothelial cell injury in cardiovascular surgery: the systemic inflammatory response. Ann Thorac Surg 1997;63:277-84.

26. Homeister JW, Lucchesi BR. Complement activation and inhibition in myocardial ischemia and reperfusion injury. Annu Rev Pharmacol Toxicol 1994;34:17-40.

27. Rinder CS, Rinder HM, Smith BR, Fitch JCK, Smith MJ, Tracey JB, et al. Blockade of C5a and C5b-9 generation inhibits leukocyte and platelet activation during extracorporeal circulation. J Clin Invest 1995;96:1564-72.

28. Lucchesi BR. Complement, neutrophils and free radicals: mediators of reperfusion injury. Arzneim-Forsch/Drug Res 1994; 44:420-32.

29. Shandelya SM, Kuppusamy P, Herskowitz A, Weisfeldt ML, Zweier JL. Soluble complement receptor type 1 inhibits the complement pathway and prevents contractile failure in the postischemic heart: evidence that complement activation is required for neutrophil-mediated reperfusion injury. Circulation 1993; $88: 2812-26$.

30. Friedrichs GS, Kilgore KS, Manley PJ, Gralinski MR, Lucchesi BR. Effects of heparin and $N$-Acetyl heparin on ischemia/reperfusion-induced alterations in myocardial function in the rabbit isolated heart. Circ Res 1994;75:701-10.

31. Tofukuji M, Stahl GL, Agah A, Metais C, Simons M, Sellke FW. Anti-C5A monoclonal antibody reduces cardiopulmonary bypass and cardioplegia-induced coronary endothelial dysfunction. J Thorac Cardiovasc Surg 1998;116:1060-8. 